\title{
'Sclerosing haemangioma' of the lung: an alternative view of its development
}

\author{
A. KENNEDY \\ From the Department of Pathology, University of Sheffield
}

SYNOPSIS 'Sclerosing haemangioma' is a name which has been applied to a group of uncommon benign pulmonary lesions characterized by their papillary nature, a sclerotic stroma containing lipid, and, in some cases, evidence of haemorrhage. There is little evidence that these lesions are really angiomatous. Studies of two examples removed surgically after being discovered as incidental radiographic findings, show that the cells lining the papillae have large vacuoles which contain whorled, electron-dense inclusions. These epithelial cells have the features of granular pneumonocytes, cells known to contain phospholipid. Both lipid and cholesterol are abundant in the stroma of both tumours and the lipid is distributed in a nodular fashion. Histochemically the lipid gives a strong reaction to stains for phospholipid and it is suggested that the lipid is derived, not from the haemorrhage, but is produced by the epithelial element of the tumour.

Sclerosing haemangioma is a name used by Liebow and Hubbell (1956) to describe five examples of a rare benign papillary lesion in the lung. The features which they describe as being characteristic of these lesions are their papillary nature, the presence of sclerosis, the accumulation of lipid and, in some cases, evidence of haemorrhage. There is little evidence that these tumours are really haemangiomas and, probably as a result of their ill-chosen name, the literature concerning them is confused by the inclusion of lesions some of which are true angiomas, xanthomas, or inflammatory pseudotumours. A study of two lesions having the features described by Liebow and Hubbell suggests that they are not haemangiomas and that their main component cell resembles the granular pneumonocyte. It may further be argued that these pneumonocytes are the origin of the substantial amount of lipid present in these lesions.

\section{Case Reports}

CASE 1

A man of 24 presented in March 1972 complaining of intermittent epigastric pain which had been present for one year. There was no relevant previous medical history and, apart from his two children who have asthma, there was no family history of chest disease. He was admitted for investigation of the gastrointestinal tract; no Received for publication 16 July 1973. alimentary lesion was found but a chest radiograph revealed a rounded opacity in the right mid-zone This was considered to be either a hamartoma or a tuberculous focus. A thoracotomy was carried ouf by Mr A. G. Norman in May 1972 and a small spherical lesion $1.5 \mathrm{~cm}$ in diameter was removed from the apex of the right lower lobe. Frozen sections confirmed that the lesion was benign and the chest was closed. The patient made an uneventful recovery and has since remained well.

\section{CASE 2}

This man of 63, employed as a school caretaker, attended a urology department in May 1972 on account of symptoms of prostatic obstruction. A prostatectomy was carried out and histological examination of the prostate showed benign hyperplasia and no evidence of tumour. However a rounded opacity had been found in the right lower lung field (fig 1) and the patient was referred to Mr A. G. Norman who removed a mass roughly $3 \mathrm{~cm}$ in diameter from the right lower lobe. The patient made an uneventful recovery and has had no further symptoms referable to his chest.

\section{Pathology}

In case 1 the tumour consisted of a solid white mass $1.5 \mathrm{~cm}$ in diameter which was not clearly demarcated from the surrounding lung. The cut surface was slightly crumbling in appearance. 


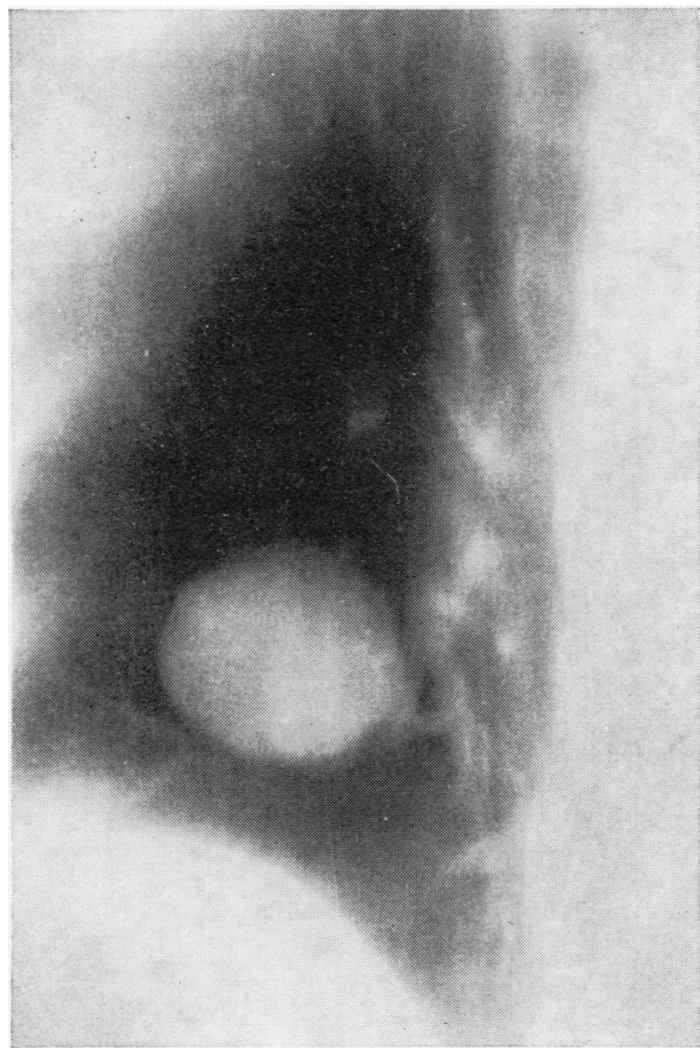

Fig 1 'Sclerosing haemangioma' of the lung: a tomogram of the right lower lung field of case 2. A rounded opacity is present just above the diaphragmatic shadow. On the medial side of the lesion are some denser areas which probably represent areas of calcification.

The larger specimen (case 2) was a lobulated ovoid lesion $4 \times 3 \times 3 \mathrm{~cm}$ covered by pleura on one surface. The outline was slightly lobulated and the cut surface was partly gelatinous but also had gritty areas of calcification.

\section{LIGHT MICROSCOPY}

Basically both tumours had the same structure consisting of closely packed papillary processes separated by ramifying epithelial-lined spaces (fig 2). The fibrous stroma of the papilae was dense often having a whorled appearance, and, in case 2 , contained areas of calcification. The lesion was not clearly demarcated from the surrounding lung (fig 3). At the edge of the lesion there was a gradual thickening both of alveolar walls and of the lining cells as the edge of the lesion is approached until in the main body of the tumour there was a closely packed mass of papillae lined by cuboidal epithelium.

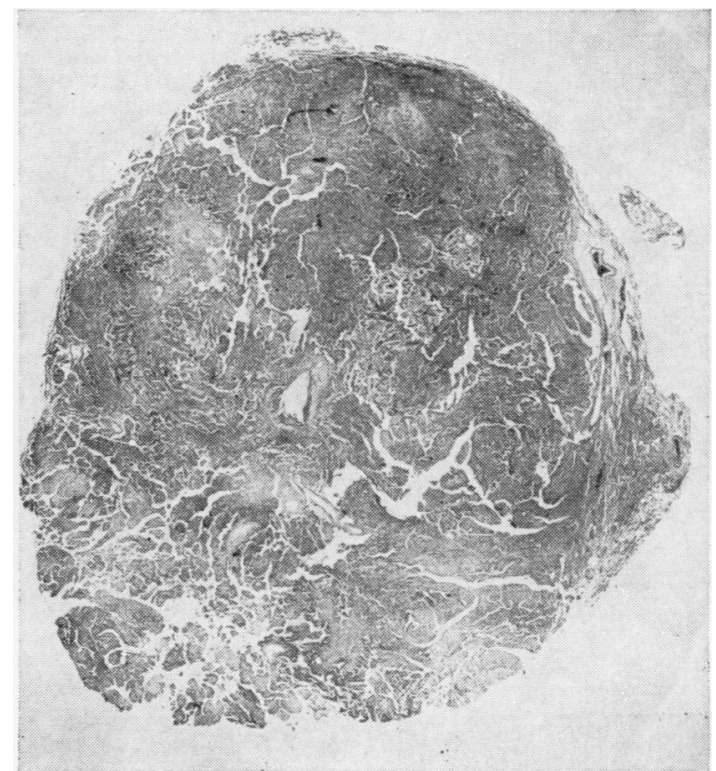

Fig 2 'Sclerosing haemangioma' of case 1. The tumour is ill defined and merges with the surrounding lung (best seen at $3 o^{\prime}$ clock). Large and small branching clefts run throughout the lesion and just to the left of the centre there is a sclerotic area containing cholesterol clefts (see fig 4). Haematoxylin and eosin $\times 6$.

The centre of the lesion consisted of hyaline acellular fibrous tissue containing large cholesterol clefts (fig 4). The papillae had a core of cellular fibrous tissue containing a variety of chronic inflammatory cells (fig 5). Only a little evidence of iron deposition was found and neither tumour contained any carbon pigment although in both cases there was carbon in the surrounding lung parenchyma. Little, if any, elastic tissue was present in the stroma even in the densly sclerotic areas in the centre, a point of distinction from the ordinary forms of pulmonary adenomatosis. Thin-walled spaces, some of which contained blood, were present but the lesions were not notable for their vascularity. No amyloid was present. In some areas the stroma was much more cellular and contained areas of vacuolated cells which in some areas seemed to merge with the cells lining the papillae.

Frozen sections viewed by polarized light and stained with Oil Red $O$ (fig 6) showed that the stroma contained abundant quantities of lipid in both cases, more lipid being present in the older patient. The lipid was present in rounded masses and in some instances it was deposited in a cyiindrical manner around thin-walled vascular spaces. The lipid deposits stained strongly by Baker's 


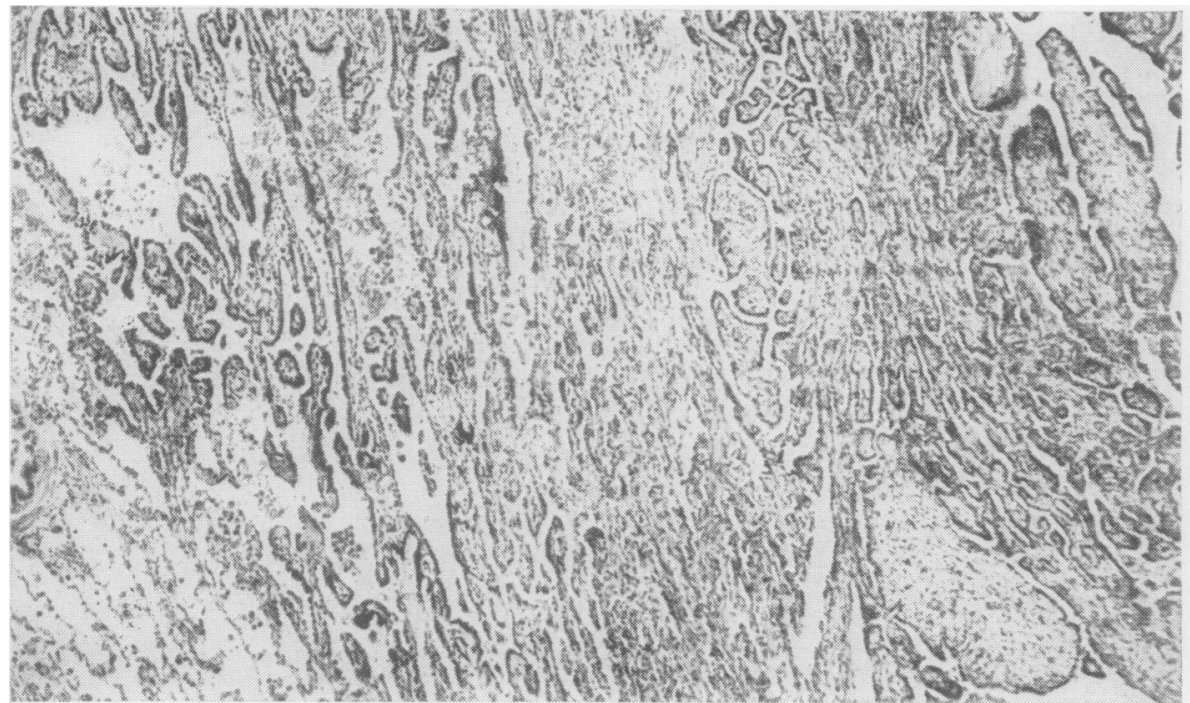

Fig 3 The edge

of the lesion. The ramifying clefts of

the tumour are seen gradually merging into normal lung. Note the thickening not only of the stroma but also of the epithelial lining of the air spaces (case 1).

H. \& E. $\times 40$.

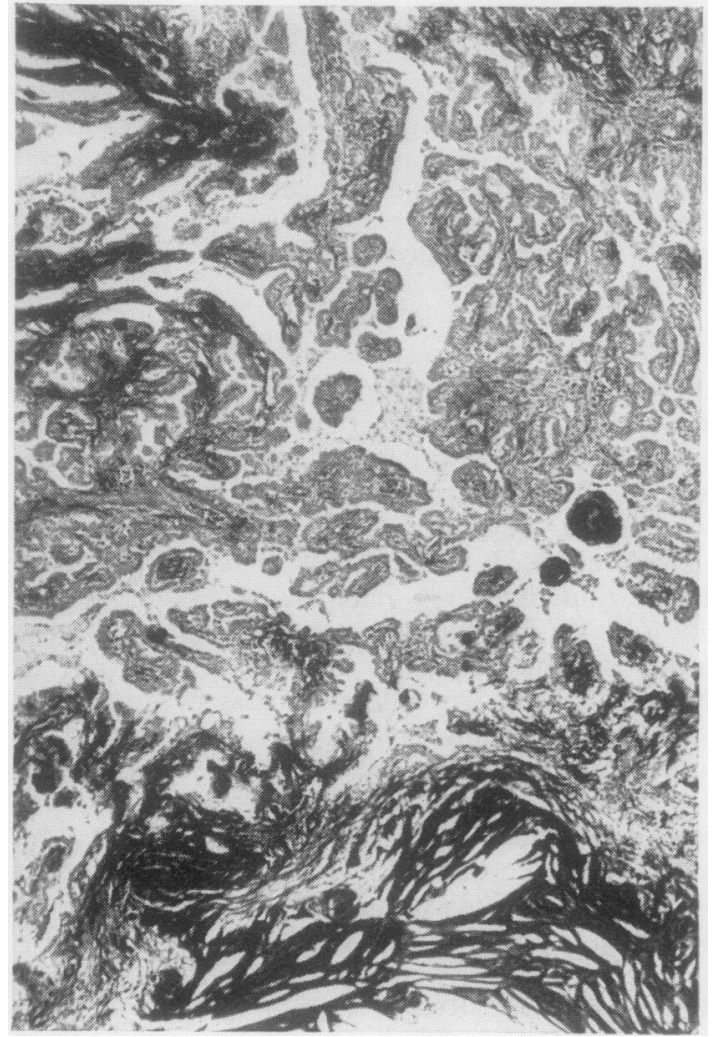

Fig 4

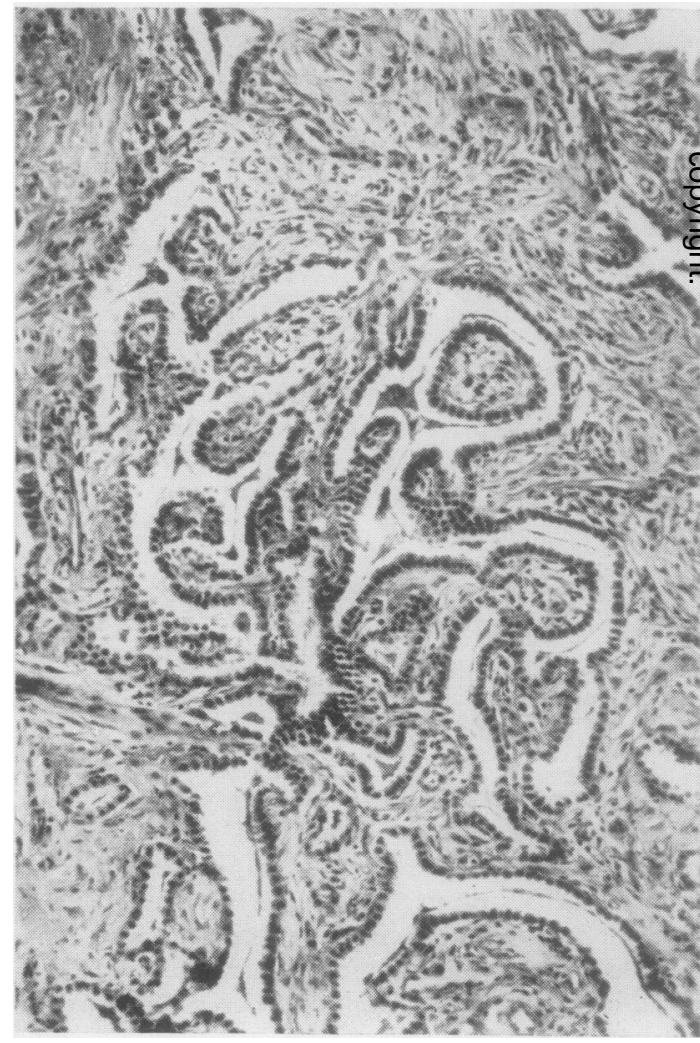

Fig 5

Fig 4 The centre of the lesion. At the bottom of the field there is a densely sclerotic area containing cholesterol clefts. The branching papillary nature of the bulk of the tumour is well shown. Van Gieson $\times 40$.

Fig 5 Typical area of branching epithelial-lined clefts and papillary processes. The stroma is cellular but does not appear to be unduly vascular. In the area shown the papillae are lined by a regular cubical epithelium with domeshaped free margins to the cells. Only scanty secretion is present in the lumina. $H \& E \times 100$. 


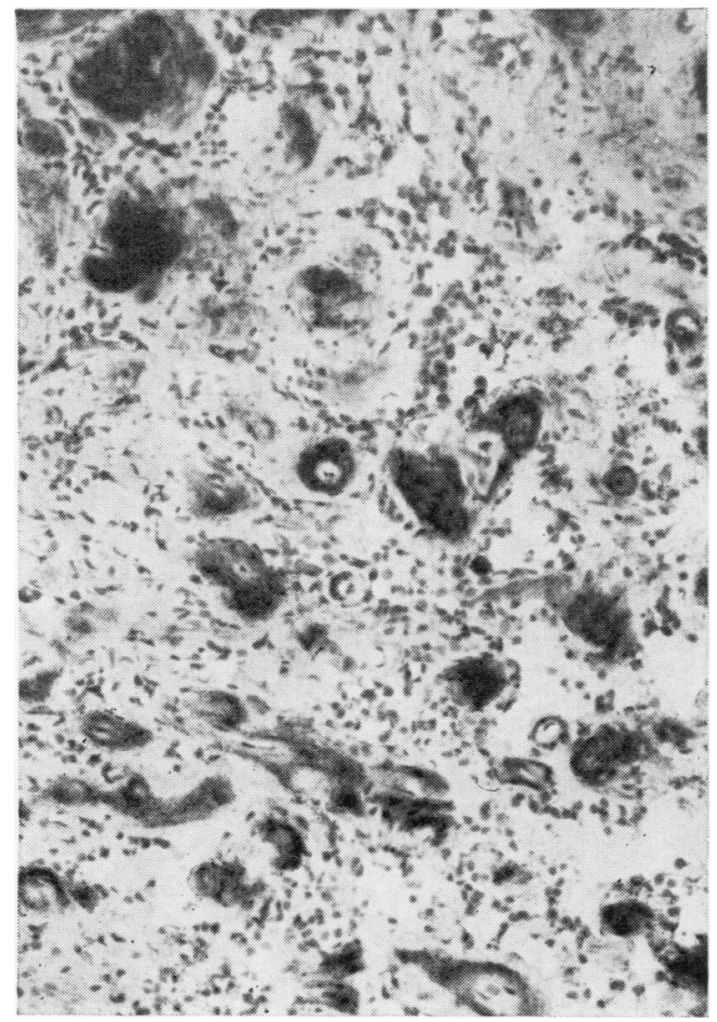

Fig 6
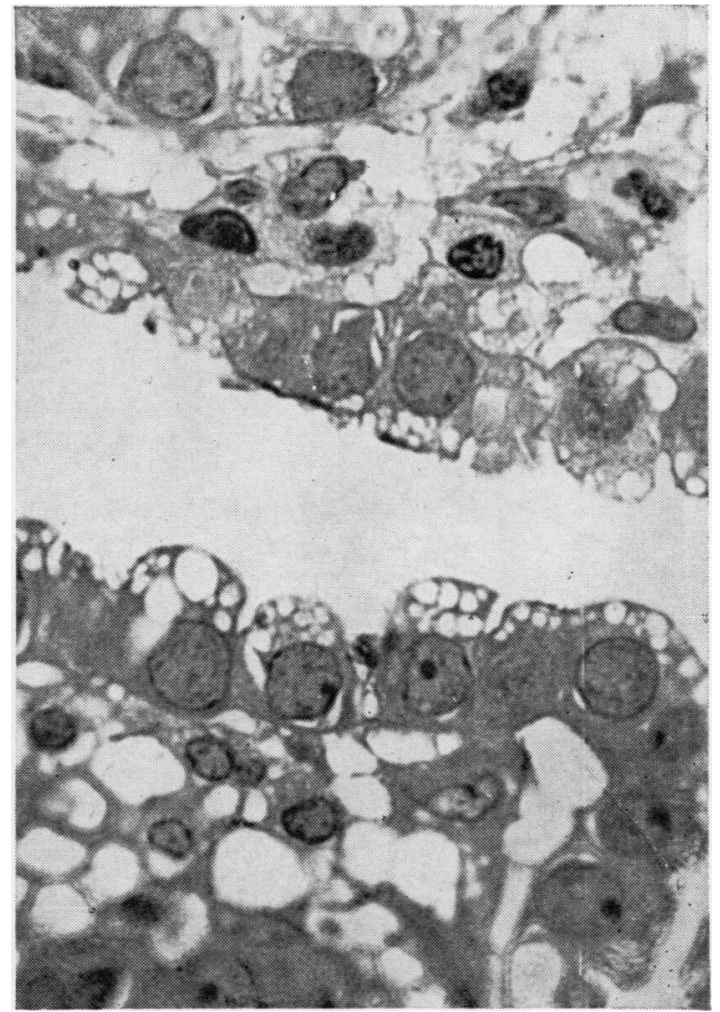

Fig 7

Fig 6 Abundant lipid is present in the stroma where it is distributed in a nodular fashion. In some areas it is arranged in a tubular fashion around spaces which appear to be small blood vessels. Frozen section, Oil Red $O \times 40$.

Fig 7 A detailed view of the type of epithelium which lined most of the clefts. The cells are of low columnar form. Their free margins are devoid of cilia and the upper part of the cytoplasm contains many clear vacuoles. Epon section $(0 \cdot 5 \mu)$. Haemalum/celestine blue $\times 1000$

haematin method and this staining was abolished by extraction with pyridine indicating the presence of phospholipid. Frozen sections also showed the refractile crystals of cholesterol.

The epithelium lining the papillae is of some interest. It is for the most part a cuboidal epithelium (fig 5) which is weakly PAS-positive. Neither argentaffin nor argyrophil cells were found but, in case 1 , there were occasional isolated groups of tall mucin-secreting cells containing acid mucopolysaccharide and occasional groups of ciliated cells but in the main the cells were cuboidal. The most remarkable feature of the lining epithelium is shown in figure 7. The cubical cells had large basally situated nuclei and their superficial parts were largely occupied by clear vacuoles.

ELECTRON MICROSCOPY

Both specimens had been fixed in formal-saline before their true identity was established but it was considered worthwhile to try and further identify the epithelial cells accepting that fixation had been far from ideal. Blocks of both specimens were washed in barbitone buffer and then fixed in osmium tetroxide. The tissues were embedded in Araldite and thin sections were stained with lead citrate and uranyl acetate for study using an AEI6 electron microscope.

The nature of the epithelial cells is shown in figure 8. The large vacuoles on the luminal aspect of the cell are well shown and although there are no cilia there are microvilli on the cell surface. Many of the vacuoles can be seen to contain laminated inclusions consisting of concentric whorls of electron-dense material (fig 9). The appearance of these cells is consistent with their being type II or granular pneumonocytes. While some authors write of papillary structures growing into vascular 


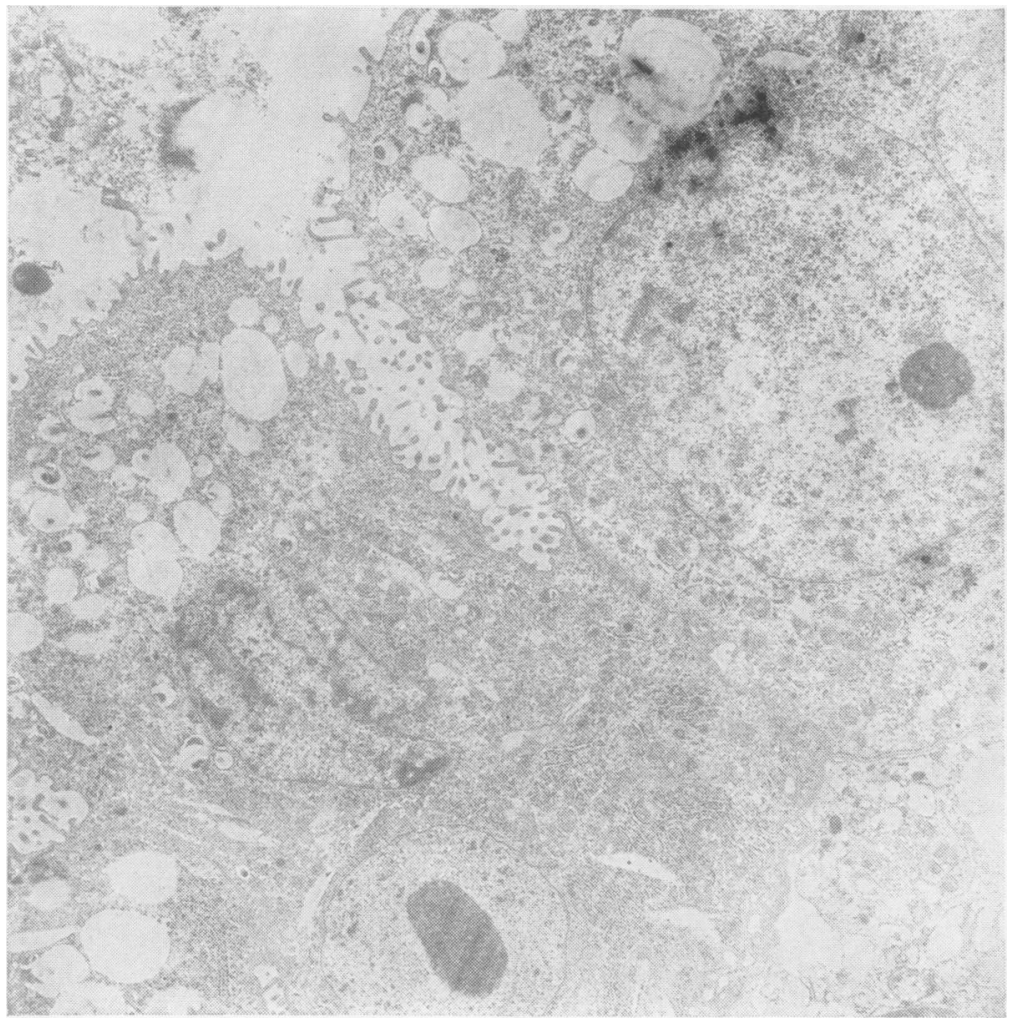

Fig 8 Two typical epithelial cells lining one of the clefts in the tumour. The cell surface has many microvilli. The vacuoles at the luminal end of the cell in the upper part of the field contain electrondense material partly as dense clumps but also in laminated form. Formalin fixation, osmium, uranyl nitrate, and lead citrate $\times 12000$

spaces it is clear that in the present cases these papillae are lined by epithelium and not endothelium and despite the name of the lesion it was not particularly vascular, endothelial-lined channels being difficult to find. However, there was some evidence of haemorrhage in the form of free red blood cells lying in the stroma. The stroma consisted of collagen with fibroblasts, histocytes, plasma cells, lymphocytes, and mast cells. Some of the histiocytes contained lipid droplets but there were considerable numbers of cells which, in every respect, resembled granular pneumonocytes. These cells were presumably in continuity with epithelium-lined spaces but such continuity was often impossible to establish. These collections of cells corresponded to the areas in which, by light microscopy, the stromal and epithelial components seemed to merge.

\section{Discussion}

By light microscopy these two tumours were not only identical with each other but are the same lesion as the cases described by Goorwitch and Madoff (1955), Liebow and Hubbell (1956), and also the case described by Hill and Eggleston (1972). Both the present lesions have the papillary pattern, the lipid and the sclerotic stroma described by Liebow and Hubbell. With the advantages of electron microscopy, however, it seems that many of ? the walled spaces are epithelial and not endothelial and that many of the cells in the cellular areas of stroma, which might seem to be histiocytic cells, are really granular pneumonocytes. It seems that the evidence of a vascular origin for this lesion is very 윽 doubtful (Spencer, 1968, 1972) and the tumours $D$ do not fill on angiography (Arean and Wheat, 1962). Both the evidence of the present study and that of $N$ Hill and Eggleston (1972) indicate that these are tumours composed mainly of granular pneumonocytes and are probably not of vascular origin. They $\underset{\omega}{N}$ appear rather to be a localized hyperplasia or $\bar{\sigma}$ perhaps congenital anomaly affecting the alveolar 0 walls and their lining cells.

Haas, Yunis, and Totten (1972) studied one case by electron microscopy and concluded that the lesion was vascular in origin. However, they paid little attention to the epithelial and lipid elements of the tumour which are such a distinctive 


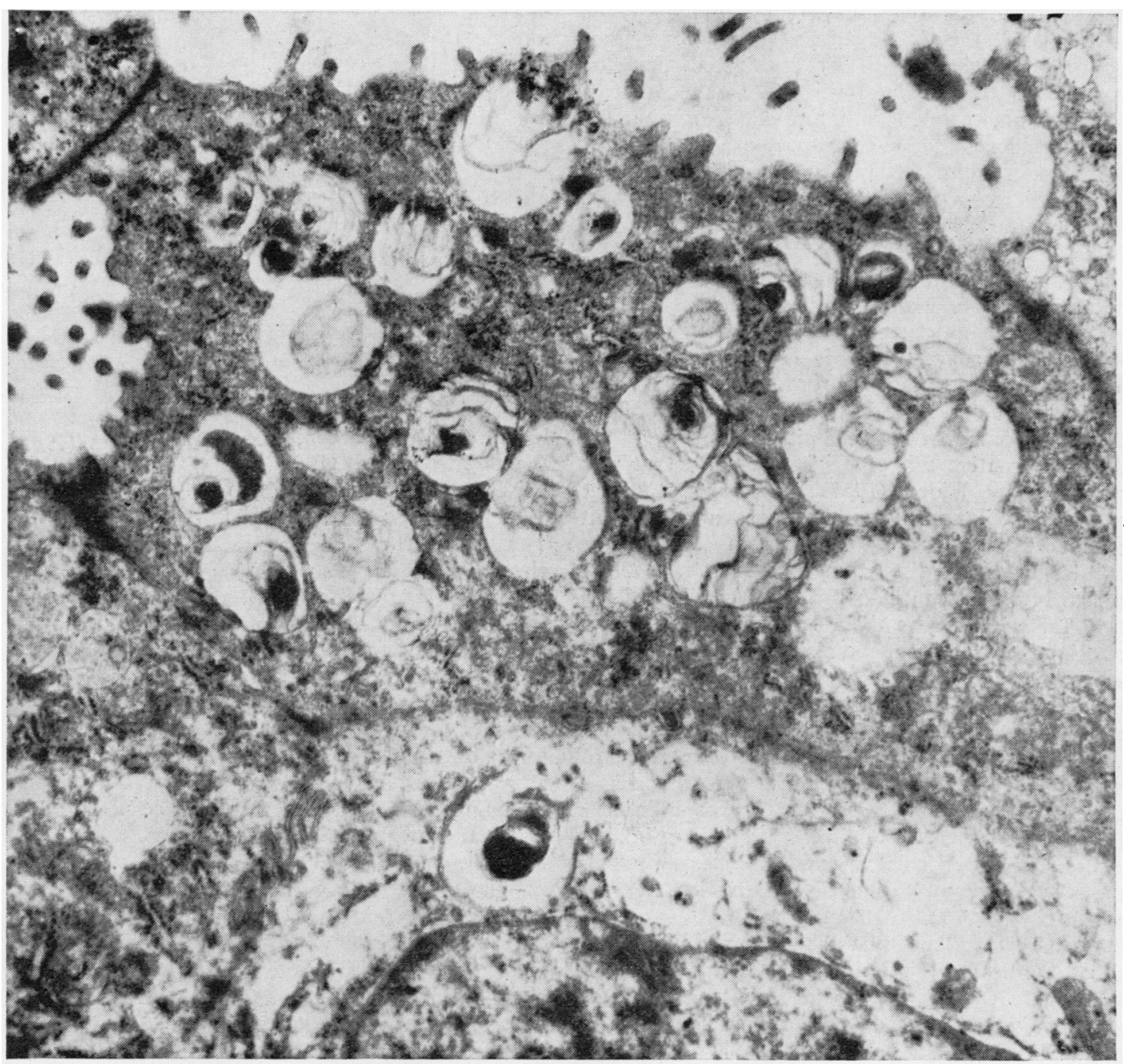

Fig 9 The luminal aspect of one of the epithelial cells. Microvilli are present and the cell has many vacuoles most of which contain laminated electron-dense structures. Uranyl nitrate-lead citrate $\times 16000$

feature of these lesions. Unfortunately their illustrations of the light microscopic appearances do not establish that their lesion is the same as in the present two cases. In my cases I have found no evidence of vascular formations such as they describe but red blood cells lying loose in the stroma were found and were presumably the result of minor haemorrhage.

Liebow and Hubbell viewed the development of these lesions in the same way as sclerosing haemangioma in the skin. They suggested that repeated haemorrhages lead to the accumulation of lipid which is such a prominent feature of the lesion. The new evidence obtained by electron microscopy of the present cases and that of Hill and Eggleston (1972) raises the possibility of a completely different explanation for the lipid present in these lesions. The predominant cell in these lesions is the granular pneumonocyte which contains large numbers of laminated inclusions; these are considered to be of phospholipid and to be related to pulmonary surfactant (Clements, 1968).

Wentworth and his colleagues (Wentworth Lynch, Fallis, Turner, Lowden, and Conen, 1968), 
described a xanthomatous pseudotumour of the lung in which they found large amounts of phospholipid and cholesterol. They considered that the composition of the lipids was quite unlike that of the xanthomata of the skin and suggested that the lipid may have originated from neuronal elements. While phospholipid is present in cell membranes and might accumulate as a result of haemorrhage, there is little haemosiderin in either of the present cases and evidence of haemorrhage is scanty. The presence of so much phospholipid in the stroma and the predominance of the cells resembling granular pneumonocytes may be related observations and suggest that it is not necessary to implicate haemorrhage in order to explain the lipid which could be a result of the activities of the epithelial component of the lesion.

An alternative cell of origin for surfactant was proposed by Niden (1967) who suggested that granular pneumonocytes phagocytosed surfactant secreted by the Clara cells. However the cells in the two lesions under discussion do not resemble Clara cells. Even allowing for the poor quality of the electron micrographs there is no evidence of the multiple spherical mitochondria and closely related endoplasmic reticulum found in Clara cells. Furthermore Clara cells often have flame-shaped cytoplasm and the cells of the sclerosing haemangioma are covered by microvilli. The absence of any affinity for silver salts implies that the cells of this lesion are unrelated to the argyrophilic cells found by Feyrter (1954) in the bronchi of infants although the bronchial argyrophil cells may sometimes contain complex inclusions (Gmelich, Bensch, and Liebow, 1967).

Perhaps 'papillary pneumonocytoma' might be a better title for this lesion than sclerosing haemangioma. However, the name of sclerosing haemangioma is useful insofar as it provides a key to the original paper by Liebow and Hubbell; in other respects it has led to much confusion and other conditions have been grouped with the lesion described by Liebow and Hubbell. In 1962 Arean and Wheat reviewed 34 cases but many of the cases reviewed in their paper or published since as cases of sclerosing haemangioma do not resemble my two cases nor the five of Liebow and Hubbell. The distinguishing feature which many of these cases lack is the presence of epithelial-lined papillary formations.

The cases published as examples of 'sclerosing haemangioma' seem to fall into three main groups: true angiomas, inflammatory and xanthomatous lesions, and lastly papillary epithelial lesions similar to the two cases described. The lesions which on review appear to have been true angiomas and

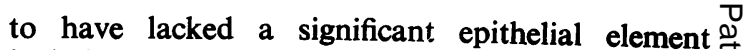
include the case which Arean and Wheat (1962) 을 described themselves and the cases described by Wollstein (1931), Hall (1935), Plaut (1940), Cooley $\underset{\vec{\rho}}{\overrightarrow{7}}$ and McNamara (1954), Rubin, Rubin, and Sicklick (1958), and Mori (1968).

Another group of cases lack both an epithelial $\frac{\bar{\sigma}}{\sqrt{\frac{5}{5}}}$ and an angiomatous component and appear to $\stackrel{\varnothing}{2}$ be inflammatory or xanthomatous lesions; some of them resemble the histiocytoma of the lung. There may however, be examples where the lipid com-. ponent is so great that the suggested epithelial $\overrightarrow{\vec{\omega}}$ origin of the lipid is obscured. This group includes ${ }^{\circ}$ the cases of Edwards and Taylor (1938), Scott, $\frac{\overline{0}}{0}$ Morrow, and Payne (1948), Umiker and Iverson i (1954), Titus, Harrison, Clagett, Anderson, and Knaff (1962), Sherwin, Kern, and Jones (1965), $\vec{\circ}$

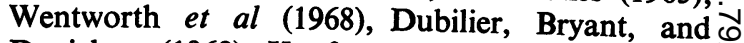
Danielson (1968), Kaufman, Goldberg, and Tyagi ${ }^{N}$ (1968), and Long, Nutt, and MacArthur (1970). 을 These authors make no mention of a papillary element in their cases which is such a feature of the cases of Goorwitch and Madoff (1955), Liebow and Hubbell (1956), Hill and Eggleston (1972), and the present two cases. It is also of interest that, in a $\overrightarrow{0}$ paper on pulmonary adenomatosis, Eversole angi Rienhoff (1959) illustrate in their fig 1 a lesion whie shows a close similarity to the present cases at which they regarded as a form of benign pulmona adenomatosis. Sclerosing haemangioma differs from adenomatosis in that the epithelial element is not $\frac{0}{8}$ arranged along the framework provided by normal $\mathrm{Q}$ lung parenchyma for in sclerosing angioma the $\overrightarrow{\overrightarrow{0}}$ papillary structures bear no resemblance to normal 3 lung. The sclerotic centre also differs from the more usual type of lung scar in two ways: there is no carbon pigment present and practically no elastic tissue both of which are usually abundant in scarred areas of lung. Growth is slow; there is no evidence that the 3 . lesion behaves as a neoplasm and it is probably a form of hamartoma. The mucosa resembles deformed bronchioles, it is papillary, there is noo cartilage, and there are occasional mucin-producing cells, so that in some ways the lesion resembles the $\frac{D}{0}$ adenomatoid hamartoma of the lung which has only been reported in infants and children (Moncrieff, $N$ Cameron, Astley, Roberts, Abrams, and Mann, 1969). .N However the 'sclerosing haemangiomas' do not $\mathrm{N}$ have a bronchial connexion and are much more $\omega$ papillary than adenomatoid hamartomas as seen in childhood (Cameron, 1972). The question of whether these are hamartomas or an acquired $\mathbb{D}$ hyperplasia of the granular pneumonocytes for the present remains unanswered.

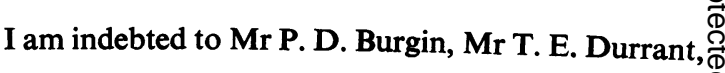


and Mrs M. Row for technical and photographic assistance. Mrs A. M. Robinson typed the manuscript and I am grateful to Professor H. Spencer for reviewing the sections.

The electron microscope was purchased from funds provided by the Yorkshire Council of the British Empire Cancer Campaign.

\section{References}

Arean, V. M., and Wheat, M. W. (1962). Sclerosing hemangiomas of the lung. Amer. Rev. resp. Dis., 85, 261-271.

Cameron, A. H. (1972). Personal communication.

Clements, J. A. (1968). Surface active materials in the lung. In The Lung, edited by A. A. Liebow and D. E. Smith, pp. 31-40. Williams and Wilkins, Baltimore.

Cooley, D. A., and McNamara, D. G. (1954), Pulmonary telangiectasia: report of a case proved by pulmonary biopsy. J. thorac. Surg., 27, 614-622.

Dubilier, L. D., Bryant, L. R., and Danielson, G. K. (1968). Histiocytoma (fibrous xanthoma) of the lung. Amer. J. Surg., 115, $420-426$

Edwards, A. T., and Taylor, A. B. (1938). Vascular endothelioma of the lung. Brit. J. Surg., 25, 487-495.

Eversole, S. L., Jr., and Rienhoff, W. F. III. (1959). Bronchiolar (peripheral lung) neoplasms and previously undescribed observations on the origin of bronchiolar carcinoma. J. thorac. Surg., 37, 750-765.

Feyrter, F. (1954). Zur Pathologie des argyrophilen Helle-ZellenOrganes im Bronchialbaum des Menschen. Virchows. Arch. path. Anat., 325, 723-732.

Gmelich, J. J., Bensch, K. G., and Liebow, A. A. (1967). Cells of Kultschitzky type in bronchioles and their relation to the origin of peripheral carcinoid tumor. Lab. Invest., 17, 88-98.

Goorwitch, J., and Madoff, I. (1955). Capillary hemangioma of the lung. Dis. Chest, 28, 98-103.

Haas, J. E., Yunis, E. J., and Totten, R. S. (1972). Ultrastructure of a sclerosing hemangioma of the lung. Cancer (Philad.), 30, 512-518.

Hall, E. M. (1935). A malignant hemangioma of the lung with multiple metastases. Amer. J. Path., 11, 343-352.
Hill, G. S., and Eggleston, J. C. (1972). Electron microscopic study of so-called 'pulmonary sclerosing hemangioma'. Cancer (Philad.), 30, 1092-1106.

Kaufman, G., Goldberg, M., and Tyagi, N. S. (1971). Non-neoplastic sclerotic pulmonary lesion (sclerosing hemangioma). Amer. Rev. resp. Dis., 104, 742-746.

Liebow, A. A., and Hubbell, D. S. (1956). Sclerosing hemangioma (histiocytoma, xanthoma) of the lung. Cancer (Philad.), 9, 53-75.

Long, F. L., Nott, D. B., and MacArthur, E. B. (1970). Xanthomatous tumour of the lung with identification of lipid content. Aust. Ann. Med., 19, 362-365.

Moncrieff, M. W., Cameron, A. H., Astley, R., Roberts, K. D., Abrams, L. D., and Mann, J. R. (1969), Congenital cystic adenomatoid malformations of the lung. Thorax, 24, 476-487.

Mori, S. (1968). Sclerosing hemangioma of the lung. Dis. Chest, 54, 381-384.

Niden, A. H. (1967). Bronchiolar and large alveolar cell in pulmonary phospholipid metabolism. Science, 158, 1323-1324.

Plaut, A. (1940). Hemangioendothelioma of the lung: report of two cases. Arch. Path., 29, 517-529.

Rubin, E. H., Rubin, M., and Sicklick, E. (1958). Circumscribed sclerosing hemangiomas of the lung appearing as 'coin' lesions. Cancer (Philad.), 11, 713-725.

Scott, H. W., Jr., Morrow, A. G., and Payne, T. P. B. (1948). Solitary xanthoma of the lung. $J$. thorac. Surg., 17, 821-825.

Sherwin, R. P., Kern, W. H., and Jones, J. C. (1965). Solitary mast cell granuloma (histiocytoma) of the lung; a histopathologic tissue culture and time lapse cinematographic study. Cancer (Philad.), 18, 634.

Spencer, H. (1968). Pathology of the Lung, 2nd ed., pp. 933-937. Pergamon, Oxford.

Spencer, H. (1972). Personal communication.

Titus, J. L., Harrison, E. G., Clagett, O. T., Anderson, M. W., and Knaff, L. J. (1962). Xanthomatous and inflammatory pseudotumors of the lung. Cancer (Philad.), 15, 522-538.

Umiker, W. O., and Iverson, L. (1954). Post inflammatory 'tumours' of the lung: report of four cases simulating xanthoma, fibroma or plasma cell tumor. J. thorac. Surg., 28, 55-63.

Wentworth, P., Lynch, M. J., Fallis, J. C., Turner, J. A. P., Lowden, J. A., and Conen, P. E. (1968). Xanthomatous pseudotumor of the lung: a case report with electron microscope and lipid studies. Cancer (Philad.), 22, 345.

Wollstein, M. (1931). Malignant hemangioma of the lung with multiple visceral foci: report of a case. Arch. Path., 12, 562-571. 